\title{
Pascal Morand, Les religions et le luxe. L'éthique de la richesse d'Orient en Occident
}

Paris, Éditions du Regard, 2012, 244 p.

Isabelle Jonveaux

\section{(2) OpenEdition}

\section{Journals}

Édition électronique

URL : http://journals.openedition.org/assr/25569

DOI : $10.4000 /$ assr.25569

ISSN : $1777-5825$

Éditeur

Éditions de l'EHESS

Édition imprimée

Date de publication : 30 décembre 2013

Pagination : 256

ISSN : 0335-5985

Référence électronique

Isabelle Jonveaux, «Pascal Morand, Les religions et le luxe. L'éthique de la richesse d'Orient en Occident », Archives de sciences sociales des religions [En ligne], 164 | 2013, mis en ligne le 12 mars 2014, consulté le 21 septembre 2020. URL : http://journals.openedition.org/assr/25569 ; DOI : https:// doi.org/10.4000/assr.25569

Ce document a été généré automatiquement le 21 septembre 2020.

(c) Archives de sciences sociales des religions 


\section{Pascal Morand, Les religions et le luxe. L'éthique de la richesse d'Orient en Occident}

Paris, Éditions du Regard, 2012, 244 p.

Isabelle Jonveaux

\section{RÉFÉRENCE}

Pascal Morand, Les religions et le luxe. L'éthique de la richesse d'Orient en Occident, Paris, Éditions du Regard, 2012, 244 p. 
1 L'ouvrage de Pascal Morand est presque un manuel pour qui s'intéresse à l'éthique économique des religions. Dix chapitres, relativement courts, sur dix grands courants religieux que nous pouvons citer: le catholicisme, le protestantisme, l'orthodoxie, le judaïsme, l'islam, l'hindouisme, le bouddhisme, le confucianisme, le taoïsme et le shintoïsme. Ce panorama des plus grandes dénominations religieuses mondiales n'est pas exhaustif, mais offre une approche satisfaisante des attitudes religieuses possibles vis-à-vis de la richesse. Nous ne referons pas ici le tableau complet des différentes éthiques religieuses possibles concernant le luxe, nous renvoyons pour cela au passionnant ouvrage de Pascal

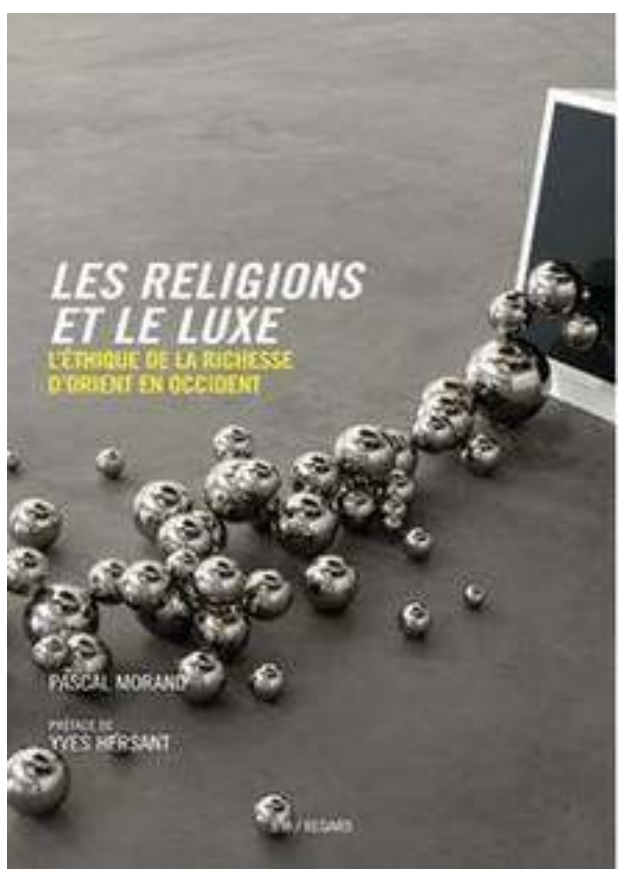
Morand.

2 L'intérêt de ce livre est donc de proposer de manière relativement condensée une approche générale sur dix courants religieux qui en feront une excellente introduction. Ainsi que le rappelle Yves Hersant, auteur de la préface, « on ne soulignera jamais assez l'influence [de la religion] - souvent invisible, il est vrai - sur les représentations et les comportements humains» (p.13) et donc notamment sur les comportements économiques. Max Weber est naturellement l'auteur incontournable concernant les liens entre économie et religion et c'est dans cette même veine que Pascal Morand étudie aussi, pour reprendre le même titre qu'un chapitre de Weber «L'éthique économique des religions du monde ». P. Morand cependant centre ici son propos non pas sur la performance économique en soi ou sur une approche générale de l'éthique économique, mais bien plus sur ce qui touche au luxe et à la richesse. Pour cela, il distingue deux acceptions du luxe : un «luxe extériorisé »(p.16) qui correspond à l'ostentation et l'utilisation de la richesse comme distinction sociale et un «luxe intériorisé » (id.) qui renvoie à une certaine aspiration au raffinement et à la volupté qui ne concerne que soi. La richesse n'est donc pas une simple question d'argent et elle va en cela au-delà de la sphère économique pour toucher aussi à l'esthétique. Ainsi que le montre Morand, le passage par l'esthétique sera dans le cas de plusieurs confessions, dont le catholicisme, une manière de purifier et donc d'accepter la richesse matérielle. Car l'attitude des religions vis-à-vis de la richesse ont aussi fortement à voir avec leur éthique générale vis-à-vis de la matérialité et finalement de la dialectique entre extramondanité et intramondanité selon les concepts de Max Weber. Il ressort en effet des différentes études de cas proposées par Pascal Morand un schéma relativement comparable entre ces différentes dénominations.

De manière générale, il est rare que l'attitude d'une religion (ou confession) soit univoque. Que ce soit le bouddhisme, par exemple, qui pose l'opposition au luxe comme consubstantielle pour reprendre le terme de l'auteur à sa définition, mais qui parallèlement considère la sécurité financière comme une forme de joie, ou l'islam dont le Coran met en garde contre l'aspiration à l'argent et à la possession tout en 
présentant des prescriptions tout à fait compatibles avec l'esprit de richesse, ou enfin l'hindouisme où le maharaja est l'incarnation du luxe et de la volupté tandis que l'ascète en est son envers exact. L'éthique économique des religions du monde semble d'une part présenter des spécificités fortement culturelles comme, selon Morand, le catholicisme héritier de la latinité, le protestantisme de l'hellenité, l'orthodoxie marquée par la culture byzantine ou encore le shintoïsme qui est une part de l'identité japonaise. Mais d'autre part, de grandes tendances semblent cependant se dessiner avec, au départ, une attitude d'emblée souvent négative ou méfiante vis-à-vis de la richesse ou au contraire conciliante ou indifférente, mais qui finalement s'accordent dans une éthique de la mesure qui justifie la richesse par sa juste utilisation, que ce soit la charité, l'équité ou le refus de l'ostentation. La richesse présenterait toujours un versant condamnable si elle écarte de la vertu et la mesure permettrait de la maintenir dans le juste chemin. Même dans le judaïsme où la richesse est pour ainsi dire encouragée, l'impératif de charité demeure une constante. Le but de la richesse comme telle est rarement approuvé par les éthiques religieuses, elle sera souvent le signe d'autre chose.

4 Mais il ressort aussi dans un certain nombre de confessions ce que nous pourrions appeler selon Ernst Troeltsch une "double éthique» qui peut être associée à deux groupes différents ou des temporalités différentes. Le bouddhisme, l'hindouisme ou enfin le catholicisme se fondent en effet sur la différence entre virtuoses, auxquels la richesse est strictement interdite, et les laïcs, pour lesquels elle sera justifiée, acceptée ou tolérée. Dans un cadre religieux qui présente cette distinction laïcs/virtuoses, le schéma sera donc toujours le même avec un refus de la richesse pour les virtuoses, ce qui signifie donc que la dépossession et l'ascétisme seraient effectivement des caractéristiques de la virtuosité religieuse. Parallèlement, on peut aussi trouver une « double éthique » temporelle, par exemple, dans l'islam, où « l'ascétisme "passager" ou "périodique" [est] destiné à se rappeler que la privation existe, et le fait de profiter raisonnablement- $d u$ confort et des plaisirs "autorisés", issus d'une fortune honnêtement gagnée.» (p. 117)

5 Un dernier élément récurrent, mais pas nécessairement constant, est la justification de la richesse à condition qu'elle serve le rite ou le Dieu lui-même. L'idée que "rien n'est trop beau pour Dieu» se retrouve en effet dans différents courants religieux, qui peuvent aussi varier selon les époques.

6 Au terme de ces dix études de cas, claires et concises, Pascal Morand actualise son propos au cadre actuel de la mondialisation. Il pose en effet la question de savoir que deviennent ces éthiques économiques religieuses différentes en système de globalisation. Si une tendance à l'homogénéisation du luxe peut alors s'observer, celleci s'accompagne nécessairement d'une permanence de types de raffinement propres à chaque culture et de l'apparition de nouveaux lieux de différenciation dans les sources de luxe et l'aspiration à l'esthétique.

7 L'ouvrage de Pascal Morand présente donc l'avantage de proposer un panorama varié de différentes confessions religieuses dans leur rapport à la richesse et au luxe, ce qui ouvre sur de possibles comparatismes relativement peu effectués dans ce domaine depuis Max Weber. 